\title{
Recent Changes to the Editorial Policies
}

Recently, significant changes have been made to the editorial policies of the journal of cancer and allied specialties (JCAS). The editorial team of JCAS felt that these changes were necessary to improve the overall scientific and editorial quality of the journal. In what follows, on behalf of the editorial team, I will briefly illustrate the nature and rationale of these revisions.

The editorial team has introduced several new editorial policies on the journal website, including policy on corrections, retractions, republications and version control, policy on scientific misconduct, expressions of concern and retraction, policy on copyrights, policy on appeal process and policy on preprints or prepublications. These policies were being practiced to some extent by the editors; however, they had not been formally implemented and advertised. These changes will help bring consistency and improve the transparency and accountability of the editorial process.

Similarly, significant changes have been made to the submission process and the peer review practice. JCAS has mandated submission of relevant reporting guideline tool by The enhancing the quality and transparency of health research network. This shall improve the reliability and content of the publications. The new peer review process necessitates an initial quality check by the editorial staff for compliance with author guidelines, ethical standards, competing interests, financial disclosures, plagiarism and other scientific and policy requirements. These steps will certainly help in improving the scientific and editorial quality of the manuscripts.

Furthermore, effective immediately, JCAS will no longer accept submissions for "Images in Oncology." The scientific information that was communicated through images alone was limited and often left readers yearning for more information about the case. Due to this, the editorial team felt that such novel or unusual images should henceforth be published as a case report. This will ensure that a detailed overview of the case is presented to the reader with necessary clinical and pathoradiological information, along with a discussion of the significance of the case in clinical practice. Simultaneously, JCAS will continue to accept original research articles and review type manuscripts.

Another major change that will take into effect right away is that JCAS will publish biannually until further notice. The editorial team felt that it was necessary to give authors and editorial team necessary time to comply and adjust to the recent structural changes that have been made to the journal. In due course, once the editorial team and authors have acclimatized, decision on increasing the publication frequency will be revisited.

\section{Khawaja Shehryar Nasir,}

BDS, MS, Diplomate American Board of Orofacial Pain, Managing Editor, Journal of Cancer \& Allied Specialties. 